\title{
Rapid Detection and Quantitation of Microcystin-Producing Microcystis Using Real-Time PCR
}

\author{
${ }^{1}$ Department of Laboratory Medicine and Pathology, University of Alberta, Canada \\ ${ }^{2}$ Provincial Laboratory for Public Health, Alberta, Canada \\ ${ }^{3}$ Institute of Microbiology, Heilongjiang Academy of Sciences, Harbin, China \\ ${ }^{4}$ Alberta Environment and Sustainable Resource Development, Alberta, Canada \\ ${ }^{5}$ Alberta Centre for Toxicology, Alberta, Canada \\ ${ }^{6}$ Department of Biological Sciences, University of Alberta, Canada \\ ${ }^{7}$ Alberta Health, Alberta, Canada
}

Yuanyuan Qiu', Tao Yuan ${ }^{2,3}$, Tatiana Kon ${ }^{2}$, Ron Zurawell ${ }^{4}$, Yu Huang ${ }^{5}$, Mark Graham ${ }^{6}$, Stephan Gabos ${ }^{7}$ and Xiaoli Pang ${ }^{1,2 *}$

\begin{abstract}
This study is to develop and validate a real-time quantitative PCR (rt-QPCR) assay for rapid quantitation of microcystin-producing Microcystis using unprocessed surface water samples collected from Alberta lakes. Microcystin synthetase gene $\mathrm{E}(m c y E)$ was targeted for microcystin-producing Microcystis and 16S rRNA was used to measure blooming level of total cyanobacteria. The assay was optimized and validated with 20 reference samples collected in 2011. The limit of detection (LOD) of rt-QPCR was 50 copies/ml for both mcyE and $16 \mathrm{~S}$ rRNA. An excellent precision was observed in 24 replicates [coefficient of variation (cv) $=1.12 \%$ for $1.0 \mathrm{E}+05$ and $=0.79 \%$ for $1.0 \mathrm{E}+03$ copies]. The rt-QPCR assay was applied for detection of $m c y E$ in 527 water samples collected from 45 lakes during the open-water season of 2012 in Alberta and 369 samples were mcyE positive. Microcystin-producing Microcystis was detected in 41 out of the 45 lakes in which, relatively high copy numbers of $m c y E(\geq 1.0 \mathrm{E}+05$ copies/ $\mathrm{ml}$ ) were determined in 9 lakes. Cyanobacteria were present in all 45 lakes determined by 16S rRNA. The rt-QPCR assay developed with specific target to $m c y E$ is sensitive, specific and robust for rapid detection and differentiation of toxic Microcystis from non-toxic cyanobacteria in surface water.
\end{abstract}

Keywords: Real-time quantitative PCR; $m c y E$ gene; Microcystin; Microcystis; Cyanobacteria

Abbreviations: rt-QPCR: Real-time Quantitative PCR; $m c y$ E: Microcystin Synthetase Gene E; PPI: Protein Phosphatase Inhibition; Ct: Cycle Threshold

\section{Introduction}

Cyanobacteria, also named blue-green algae, are prokaryotic photosynthetic microorganisms that grow in warm, eutrophic surface waters. In Alberta, Canada, many lakes and reservoirs are eutrophic and support significant blooms of cyanobacteria during summer and early fall. It has been reported that on average $59 \%$ of the cyanobacterial blooms contain toxins [1]. Microcystin is the most common and prevalent cyanobacterial toxin and is produced mainly by species of Microcystis, Planktothrix and Anabaena. Microcystin is a small monocyclic heptapeptide with seven amino acids and is soluble and stable in water [2]. The amino acids D-glutamate and Add a play important roles in interaction with protein phosphatases and thus are critical for the toxicity of microcystin $[3,4]$. Microcystin poses a potential hazard to humans and animals through its inhibition on eukaryotic protein phosphatase 1 and $2 \mathrm{~A}$ in hepatocytes, which results in gastrointestinal illness, severe liver damage and dysfunction, and possible carcinogenesis [5-8]. Microcystin is synthesized by microcystin synthetase enzyme complex encoded by mcy gene cluster via a nonribosomal thio-template pathway $[9,10]$. The $m c y$ gene cluster contains 10 genes, namely mcy A to $m c y \mathrm{~J}$, which have been fully sequenced and characterized in species Microcystis, Planktothrix and Anabaena [10-13].

Currently, the most common method for detecting and monitoring cyanobacteria is light microscopy examination of cell morphology and abundance; and methods for quantifying microcystin comprise enzyme inhibition assay, immunological and analytical assays such as the protein phosphatase inhibition (PPI) assay, enzyme-linked immunosorbent assays (ELISA) and high-performance liquid chromatography (HPLC).

Microscopic techniques cannot differentiate toxin-from non-toxinproducing species of cyanobacteria, although potential toxin-producing species can be identified taxonomically using the morphological species concept. Other assays are either time-consuming, requiring sophisticated instruments, or lack of sensitivity and specificity [14]. Therefore, development of a rapid, quantitative, cost-effective and specific method is needed for monitoring the prevailing level of toxinproducing cyanobacteria in environmental water.

Real-time quantitative PCR (rt-QPCR) has been used for a decade in clinical microbiology diagnostics because of its advantages of fast speed, high sensitivity and specificity, and less risk of cross contamination [15]. However, this method hasn't been routinely used in the diagnostics of microorganisms in environmental samples. With the increasing numbers of complete genomic sequences and knowledge of biosynthetic genes involved in toxin production, rtQPCR has great potential for quantitation of toxin gene levels as well as identification of toxin-producing cyanobacterial species. The mcy gene

*Corresponding author: Xiaoli Pang, Provincial Laboratory for Public Health, University of Alberta Hospitals, WMC 2B4.58, 8440-112 Street Edmonton, AB, T6G 2J2, Canada, Tel: +1 780407 3483; Fax: +1 780407 8984; E-mail: Xiao-Li.Pang@albertahealthservices.ca

Received March 26, 2013; Accepted June 21, 2013; Published June 24, 2013

Citation: Qiu Y, Yuan T, Kon T, Zurawell R, Huang Y, et al. (2013) Rapid Detection and Quantitation of Microcystin-Producing Microcystis Using Real-Time PCR. J Mol Biomark Diagn S5: 006. doi:10.4172/2155-9929.S5-006

Copyright: (c) 2013 Qiu Y, et al. This is an open-access article distributed unde the terms of the Creative Commons Attribution License, which permits unrestricted use, distribution, and reproduction in any medium, provided the original author and source are credited 
clusters have been reported as molecular markers for identification of microcystin-producing cyanobacteria [16-18]. The carboxyl group of the D-glutamate side chain is present in all known variants of microcystin $[19,20]$. The $m c y E$ gene is responsible for the activation and condensation of D-glutamate with Adda moiety [10,13], which can be used as a specific target for microcystin-producing cyanobacteria.

Due to potential health risks and biological hazards caused by toxin-producing cyanobacterial blooms, the Government of Alberta commenced monitoring for prevailing levels of microcystin in recreational lakes and reservoirs in 2005. Data collected from 4 open water seasons (2005-2008) revealed that microcystins occur in a majority of Alberta lakes and reservoirs [21]. Since up to $95 \%$ of cyanobacterial blooms formed by Microcystis sp. were found to be toxic [22], the $m c y E$ gene is our primary focus. The purpose of this study is to develop and validate a rapid and simple rt-QPCR assay for detection and quantitation of toxin-producing Microcystis in Alberta lakes using specific primers to target $m c y E$ gene fragment of Microcystis.

\section{Materials and Methods}

\section{Reference samples for method development}

Twenty water samples collected from 15 Alberta lakes during the summer of 2011 were provided by Alberta Health Services' (AHS') Beach Monitoring Program. These 20 samples (including 17 microcystin positive and 3 negative samples), which were previously analysed for microcystin using PPI assay by the Alberta Centre for Toxicology (ACFT), were used for optimization of sample preparation and the rt-QPCR assay.

Powdered green algae (Chlorella protothecoids) were kindly provided by Dr. William McCaffrey (Department of Chemical and Materials Engineering, University of Alberta). The final concentration $100 \mu \mathrm{g} / \mu \mathrm{l}$ was prepared in water and assayed using rt-QPCR with $m c y E$ gene specific primers.

Three strains of Microcystis aeruginosa cultured in modified BG11 medium were purchased from the Canadian Phycological Culture Centre (CPCC, Waterloo, Canada). CPCC124 is a non-toxic strain isolated from Ontario lakes (Canada), while CPCC299 and CPCC300 are toxic strains isolated from Alberta lakes (Canada). The cell numbers of these strains were kindly provided by Dr. Rolf Vinebrooke (University of Alberta). These three strains of Microcystis were used in the method development for specificity assessment.

\section{Lake-water samples for method validation}

Lake-water samples were collected by AHS' Beach Monitoring Program from 45 lakes/beaches across Alberta during summer/ fall (June-Oct) of 2012. Generally, water was collected with a depth integrated sampling tube from the surface to a depth of 20 " from several sites along a beach area and combined to create a single composite sample. Some samples were simple grab samples collected by dipping a sampling container several inches below the surface. An aliquot of 50 $\mathrm{ml}$ was either frozen at $-20^{\circ} \mathrm{C}$ and then shipped to the lab on dry-ice or sent to the lab fresh on ice within $48 \mathrm{hrs}$ of collection.

\section{Development of Real-time Quantitative PCR}

\section{Optimization of sample preparation for amplification}

Two sample preparation methods were used for the 20 reference samples to optimize sample volume for DNA extraction as followed: 1) a 2-ml aliquot of water was centrifuged at $8,000 \mathrm{rpm}$ for $6 \mathrm{~min}$ and the supernatant was collected. The pellet was dissolved in $200 \mu \mathrm{l}$ TE buffer (10 mM Tris.Cl, $1 \mathrm{mM}$ EDTA, pH 8.0). The supernatant and pellet solution $(200 \mu \mathrm{l} /$ each $)$ were used for DNA extraction; and 2) in order to simplify methods and reduce sample volume, $400 \mu \mathrm{l}$ of water without any manipulation was directly used for DNA extraction. DNA yields from two different methods were quantified by rt-QPCR assay. After comparison of two methods, method 2 was adopted and applied in all remaining sample preparation for rt-QPCR. DNA was extracted using a Qiagen DNA mini kit according to the manufacturer's instruction (QIAGEN Inc., Ontario, Canada). DNA was eluted with $50 \mu$ l elution buffers and stored at $-20^{\circ} \mathrm{C}$ until further processing for rt-QPCR.

\section{Real-time QPCR for detection of $m c y E$ gene and $16 S r R N A$}

rt-QPCR for $\boldsymbol{m c y E}$ gene: Primers and TaqMan probe targeting $m c y E$ gene of Microcystis spp were previously described by Sipari [23]. The forward primer 5'-AAGCAAACTGCTCCCGGTATC-3' and the reverse primer 5'-CAATGGGAGCATAACGAGTCAA-3' were expected to yield a $120 \mathrm{bp}$ amplicon. TaqMan probe: 5'-CAATGGTTATCGAATTGACCCCGGAGAAAT-3' with a FAM 5 end label and a TAMARA 3' end label was used for real-time detection during the PCR reaction. Twenty $\mu$ of the PCR reaction mixture containing $5 \mu \mathrm{l}$ extracted DNA, $0.5 \mu \mathrm{M}$ of each primer, $0.125 \mu \mathrm{M}$ probe, and $1 \times$ LightCycler TaqMan Master Mix (Roche Diagnostics, Laval, Canada) was added to the capillaries (Roche Diagnostics). The capillaries were mounted onto the carousel, centrifuged and loaded into the Light Cycler 1.0 instrument (Roche, Canada). The thermal cycles were as follows: an initial $10 \mathrm{~min}$ at $95^{\circ} \mathrm{C}$, followed by 45 cycles of $10 \mathrm{sec}$ denaturing at $95^{\circ} \mathrm{C}, 20 \mathrm{sec}$ annealing at $58^{\circ} \mathrm{C}$, and $1 \mathrm{sec}$ extension at $72^{\circ} \mathrm{C}$. Data analysis was automatically performed using the Light Cycler software (version 4.0).

rt-QPCR for $16 S$ rRNA: In order to detect cyanobacteria in general, the primer was designed from conserved sequences of $16 \mathrm{~S}$ rRNA as previously described by Lin $S$ [24]. The forward primer 5'-CGGACGGGTGAGTAACGCGTG-3' and the reverse primer 5'-CCCATTGCGGAAAATTCCCC-3' were expected to yield a 258bp amplicon. SYBR ${ }^{\circledR}$ Green I System was utilized for $16 \mathrm{~S}$ rRNA. The rtQPCR reaction was performed in a total volume of $20 \mu \mathrm{l}$ containing 1 $\mathrm{x}$ LightCycler FastStart SYBR Green I Master mix (Roche Diagnostics), $3 \mathrm{mM} \mathrm{MgCl} 2,0.5 \mu \mathrm{M}$ of each primer and $5 \mu \mathrm{l}$ extracted DNA. Amplification for cyanobacteria $16 \mathrm{~S}$ rRNA consists of the denaturation for $10 \mathrm{~min}$ at $95^{\circ} \mathrm{C} ; 40$ cycles of $10 \mathrm{~s}$ at $95^{\circ} \mathrm{C}, 5 \mathrm{~s}$ at $58^{\circ} \mathrm{C}, 10 \mathrm{~s}$ at $72^{\circ} \mathrm{C}$, followed by the melting profile. For data analysis, melting temperature (Tm), fluorescence-d [F1]/dT under melting curve window and cycle threshold $(\mathrm{Ct})$, which is defined as the fractional cycle number where the fluorescence passed the fixed threshold in quantitation window, were selected as the evaluating parameters. Readout of the reaction with $\mathrm{Tm}$ of $85-87^{\circ} \mathrm{C}$, fluorescence-d [F1]/dT above 1.5 , and $\mathrm{Ct}$ value below 38.00 against a baseline of fluorescence signal at 2.0 was defined as positive.

\section{Development of standard curve for quantitation}

The standard curve was established as a correlation between the $m c y E$ gene copy numbers and the $\mathrm{Ct}$ [25]. A $529 \mathrm{bp}$ fragment was amplified using primers designed from the same $m c y E$ gene region covering the full length of targeting $m c y E$ sequence. Primer sequences for the $m c y E$ fragment were forward: 5'AACCCGAAATGACTCAAGAAAAA-3', reverse: 5'-TCAAAAATACCGATAGGATGTT-3'. The fragment DNA was purified from the PCR product using a QIA quick PCR purification kit (QIAGEN Inc.) and quantified using NanoDrop 2000 spectrophotometer (Thermo Scientific, Canada). The molecular weight 
of fragment DNA was calculated. A series of 10 -fold dilutions $(2.0 \mathrm{E}+00$ to $2.0 \mathrm{E}+09$ copies) were analyzed by real-time PCR to identify the dynamic range and establish standard curve for quantitation of $m c y E$ and 16S rRNA genes. The purified DNA was dispensed in aliquots containing $1.0 \mathrm{E}+03$ or $1.0 \mathrm{E}+05$ copies per $\mu \mathrm{l}$ as positive control and stored at $-70^{\circ} \mathrm{C}$ until use

\section{Development of an internal control for monitoring PCR inhibition}

Salmon testes DNA (Cat \# D1626, Sigma, Canada) was dissolved in water at a concentration of $1 \mathrm{mg} / \mathrm{ml}$ with stirring at room temperature for 2-4 hours. A real time PCR for detection of salmon testes DNA was previously described [26]. An appropriate amount of salmon DNA identified in $\mathrm{Ct}=30$ using real time PCR was used for monitoring inhibition of $r t$-QPCR. Briefly, $5 \mu \mathrm{l}$ salmon DNA $(\mathrm{Ct}=30)$ was added into $400 \mu \mathrm{l}$ water sample followed by DNA extraction and real-time PCR was performed for detection of salmon DNA. Inhibition was defined as a delay of $\mathrm{Ct}$ by 3 cycles as compared to a distilled water control spiked with the salmon DNA.

\section{Evaluation of the sensitivity, specificity and precision of rt-} QPCR

PCR efficiency was defined as $100 \%$ with the slope value at -3.3 for 10-fold serial dilution [27] and was evaluated in this assay by plotting the Ct values of a series of 10 -fold dilution of $m c y E$ fragment (529 bp) against the dilution factor. The specificity of real-time PCR was evaluated by three Microcystis strains purchased from CPCC and one green algae Chlorella protothecoids. The sensitivity of our assay was assessed by serial dilutions ( $2.0 \mathrm{E}+00$ to $2.0 \mathrm{E}+09$ copies) of the $m c y E$ fragment. The precision of rt-QPCR was analyzed using Ct values generated from replicates of positive controls performed in different days. A correlation between the results from the rt-QPCR and PPI assay was analyzed to further validate the reliability of the rt-QPCR method against the well-established method of PPI.

\section{Statistical analysis}

Correlation between rt-QPCR and PPI assays for quantitation of microcystin was analyzed using the Pearson Product - Moment test. The precision of the rt-QPCR was expressed as coefficient of variation (CV) and $95 \%$ confidence interval.

\section{Results}

\section{Evaluation of the rt-QPCR assay}

Very good sensitivity of the $m c y E$ gene quantitation was revealed in a linear log-range from $2.0 \mathrm{E}+00$ to $2.0 \mathrm{E}+09$ copies per reaction when selected primers/probes were used in the rt-QPCR reaction (Figure 1). The limit of detection was 50 copies $/ \mathrm{ml}$ and the limit of quantitation range was $5.0 \mathrm{E}+02$ to $5.0 \mathrm{E}+10$ copies $/ \mathrm{ml}$ for the assay. The rt-QPCR efficiency was observed as 1.994 adjusting from the standard curve. Excellent precision was observed. The coefficient variation of $\mathrm{Ct}$ value from 24 replicates of rt-QPCR was $1.12 \%$ for $1.0 \mathrm{E}+05$ and $0.79 \%$ for $1.0 \mathrm{E}+03$, respectively.

16S rRNA was detected in all three Microcystis aeruginosa strains but not in green algae Chlorella protothecoids (Table 1). No amplification of $m c y E$ gene was observed in non-toxic Microcystis CPCC124 and Chlorella protothecoids using the rt-QPCR assay with $m c y E$ primers and probe targeting to the Microcystis, while $4.1 \mathrm{E}+07$ copies $/ \mathrm{ml}$ of $m c y E$ gene in CPCC299 and $9.78 \mathrm{E}+05$ copies $/ \mathrm{ml}$ of $m c y E$ gene in CPCC300 were detected respectively (Table 1).

\section{Optimization of sample preparation}

Comparative results of quantitative $m c y E$ gene copy numbers from 19 reference samples assayed parallel using rt-QPCR were observed between two sample preparation methods and showed in figure 2 . Direct extraction from water samples without any pre-processing was adopted as the optimized method for monitoring $m c y E$ gene of Microcystis in Alberta lakes using rt-QPCR assay.

\section{Comparison of rt-QPCR and PPI for detection of toxin- producing Microcystis}

Overall, rt-QPCR detected 13 out of 17 (76\%) microcystin positive samples previously tested by PPI. There was $100 \%$ (4/4) agreement in samples containing high concentrations of microcystin $(>1.0 \mu \mathrm{g} / \mathrm{L})$, but only $69 \%(9 / 13)$ in samples with lower toxin levels $(<1.0 \mu \mathrm{g} / \mathrm{L})$ as assayed by PPI (Table 2). Of 3 samples determined to contain no microcystin by PPI, 2 of these were positive by rt-QPCR (Table 2). There was a correlation between microcystin concentrations by PPI and $m c y E$ numbers by $r t$-QPCR from the direct extraction $\left(r^{2}=0.27, p\right.$ $<0.05$ ) in 19 reference samples (one sample was excluded due to PCR inhibition).

\section{Detection of Microcystis $m c y E$ gene in lake-water samples}

A total of 527 water samples were tested for $m c y E$ gene using our optimized direct sample preparation method and validated specific $m c y E$ primers and probes. Of these, 369 samples (70\%) were $m c y E$ gene positive and 158 samples were $m c y E$ gene negative in which no PCR inhibition was detected using internal control salmon DNA. Among the 45 lakes sampled, $m c y E$ gene was not detected in 4 lakes (9\%), occasionally detected at a very low level $(m c y E$ gene $<500$ copies $/ \mathrm{ml})$ in 9 lakes $(20 \%)$, and frequently detected at moderate to high level (500 - $3.4 \mathrm{E}+06$ copies $/ \mathrm{ml})$ in 32 lakes $(71 \%)$ during the sampling period. These results were consistent with previous AESRD report showing that up to $75 \%$ of Alberta lakes contained microcystin at least in one occasion during the whole open water (May-Oct) season [21]. In 2012, blue-green algae health risk advisories were issued by AHS for 15 Alberta lakes based on visual inspection of cyanobacterial blooms along public recreation shorelines. Our rt-QPCR results confirmed

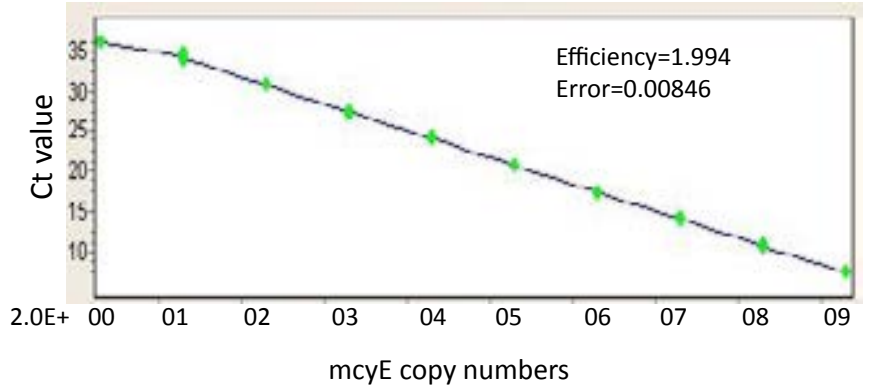

Figure 1: Ct value obtained from real-time PCR for serial dilutions of mcyE DNA fragment.

\begin{tabular}{|c|c|c|c|c|}
\hline & \multicolumn{3}{|c|}{ Microcystis aeruginosa strains } & Algae \\
\hline & CPCC124 & CPCC299 & CPCC300 & Chlorella Protothecoids \\
\hline Cell count/ml & $2.97 \mathrm{E}+07$ & $2.14 \mathrm{E}+08$ & $4.2 \mathrm{E}+07$ & N/A \\
\hline mcyE gene copy/ml & negative & $4.10 \mathrm{E}+07$ & $9.78 \mathrm{E}+05$ & negative \\
\hline 16S rRNA copy/ml & $1.75 \mathrm{E}+06$ & $7.5 \mathrm{E}+06$ & $5.78 \mathrm{E}+05$ & negative \\
\hline
\end{tabular}

Table 1: rt-QPCR of three Microcystis aeruginosa strains and one algae strain for mcyE and 16S rRNA. 


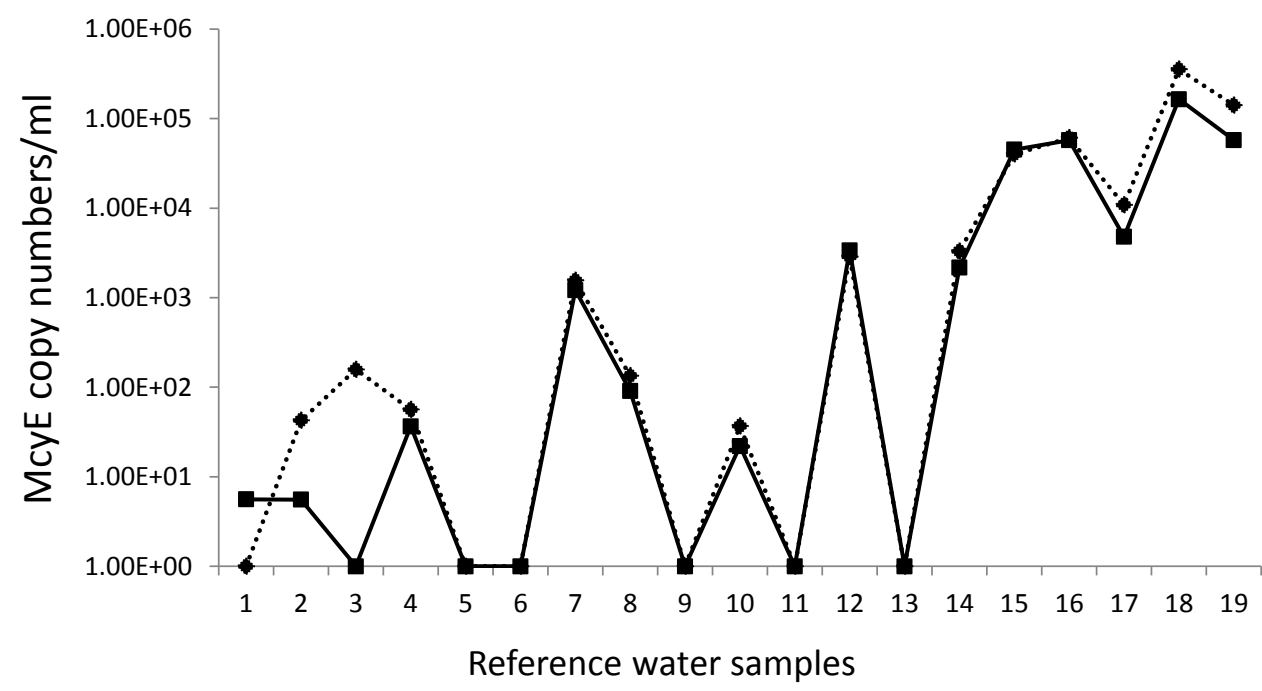

Figure 2: mcyE copy numbers from 19 reference water samples of 2011. Microcystis mcyE copy numbers were determined by rt-QPCR, which was showed as mcyE copy numbers per millilitre. The sum of $m c y E$ copy numbers ( $\mathbf{a})$ from centrifuge supernatant and centrifuge pellet were compared with $m c y E$ copy numbers from direct extraction $(\bullet)$.

\begin{tabular}{|c|c|c|c|c|}
\hline & \multicolumn{3}{|c|}{ Microcystin concentration equivalent by PPI assay } \\
\hline rt-QPCR for $m c y E$ & Negative $(<0.05 \mu \mathrm{g} / \mathrm{L})$ & $0.05 \mu \mathrm{g} / \mathrm{L} \leq$ Microcystin $<1 \mu \mathrm{L} / \mathrm{L}$ & Microcystin $\geq 1 \mu \mathrm{g} / \mathrm{L}$ \\
\hline Negative & 1 & 4 & 0 \\
\hline Positive & 2 & 9 & 5 \\
\hline Total & 3 & 13 & 15 \\
\hline
\end{tabular}

Table 2: rt-QPCR and PPI results of 20 reference samples.

that 10 out of the 15 lakes in the list of advisories had high $m c y E$ copy numbers which was greater than $1.0 \mathrm{E}+05$ copies $/ \mathrm{ml}$.

\section{Quantitation of toxin-producing Microcystis in individual lakes}

Two lakes (Pine and Pigeon Lakes) with health risk advisories issued by AHS in 2012 were used to assess the spatial variation of Microcystis $m c y E$ gene along different beach areas within the same lake. The $m c y E$ gene copy numbers at the Pine Lake's Leisure Camp beach and Green Acre beach (A) and Pigeon Lake's Mission beach and Zeiner Park beach (B) are shown in Figure 3. During the open-water season, the highest $m c y E$ copy numbers were $4.0 \mathrm{E}+05 / \mathrm{ml}, 2.1 \mathrm{E}+05 / \mathrm{ml}, 2.6 \mathrm{E}+05 /$ $\mathrm{ml}$ and $3.0 \mathrm{E}+04 / \mathrm{ml}$ detected in Leisure Camp beach, Green Acre beach, Mission beach and Zeiner Park beach, respectively. The levels of Microcystis at both Pine Lake beaches were similar during the season, with peaks in early Aug and mid-Sep. However, observed Microcystis levels at the two Pigeon Lake beaches differed during the season, with peaks occurring in late July, early Aug and early Sep at Mission beach compared to early Aug and mid-Sep at Zeiner Park beach.

\section{Cyanobacteria levels in lake-water samples}

Total cyanobacteria was determined for all the lake-water samples using rt-QPCR with cyanobacterial specific 16S rRNA primers [24]. All 527 samples detected positive for cyanobacterial 16S rRNA with the highest level at $3.2 \mathrm{E}+06$ copies $/ \mathrm{ml}$, suggesting that cyanobacteria were present in all lakes during the sampling period. Moreover, high $16 \mathrm{~S}$ rRNA copy numbers $(>1.0 \mathrm{E}+05)$ were detected in samples from all 15 lakes issued with cyanobacteria health risk advisories. Figure 4 shows relatively high levels of cyanobacteria were observed in both Pine (A) and Pigeon Lakes (B) from June to October 2012. The highest
$16 \mathrm{~S}$ rRNA copy numbers were $1.2 \mathrm{E}+06 / \mathrm{ml}, 1.5 \mathrm{E}+06 / \mathrm{ml}, 4.4 \mathrm{E}+05 / \mathrm{ml}$ and $9.8 \mathrm{E}+05 / \mathrm{ml}$ for Leisure Camp beach, Green Acre beach, Mission beach and Zeiner Park beach, respectively (Figure 4A and 4B). The proportion of microcystin-producing Microcystis relative to the total cyanobacteria in these two lakes ranged broadly from 0 to $62 \%$. More abundant cyanobacteria were observed in Pine than Pigeon Lake and both beaches in each lake had similar trend in cyanobacteria levels during sampling period.

\section{Discussion}

PCR based methods for detection of Microcystis in environmental water samples were first described using mcy gene clusters [28,29]. A positive correlation between Microcystis mcyE gene copy numbers and microcystin concentrations was reported using the samples from two Finnish lakes, indicating that $m c y E$ gene could be used as an alternative biomarker for toxin-producing Microcystis [17]. In this study, the rtQPCR method targeting $m c y E$ gene has been further evaluated and validated in comparison with classic method of PPI assay.

To measure the prevailing levels of Microcystis and its fluctuation during the open-water season, it is important to know the proportion of Microcystis relative to total cyanobacteria in individual lakes. Detection and quantitation of $16 \mathrm{~S}$ rRNA gene was developed and added to the rt-QPCR assay for estimation of total cyanobacterial population. Using the relative level of $m c y E$ gene versus $16 \mathrm{~S}$ rRNA, a trend of toxinproducing Microcystis population in the cyanobacterial bloom in individual lakes can be estimated, allowing for further assessment of risks caused by Microcystis.

The rt-QPCR assay developed and validated in this study is capable of detecting and quantifying microcystin-producing Microcystis 


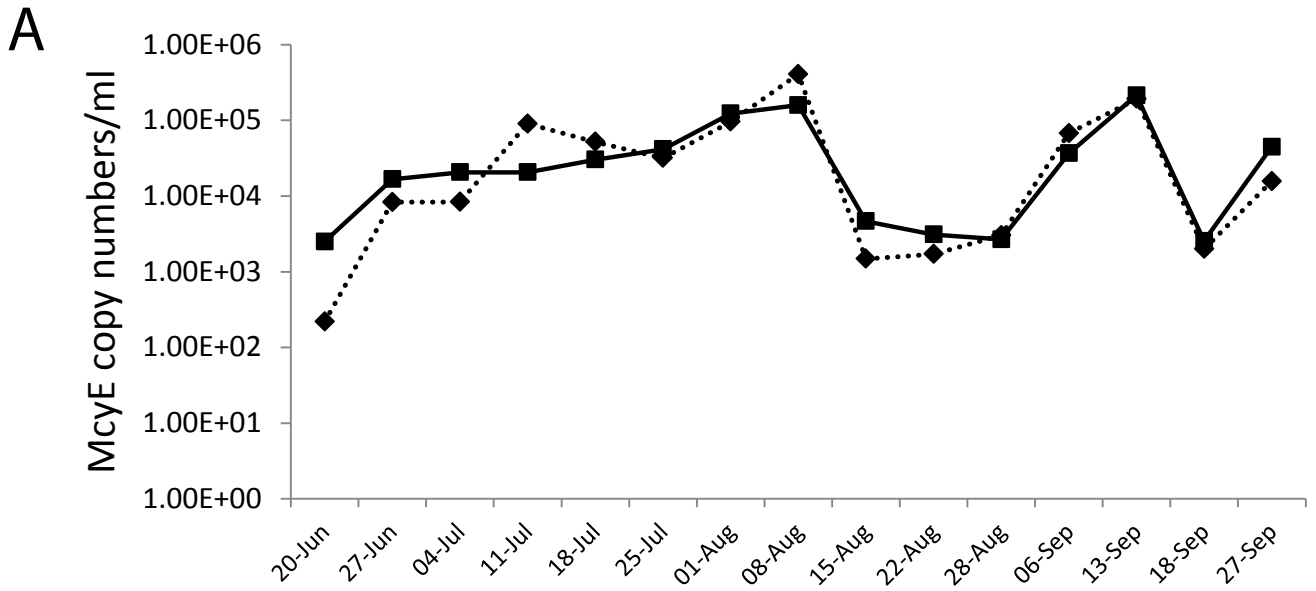

B

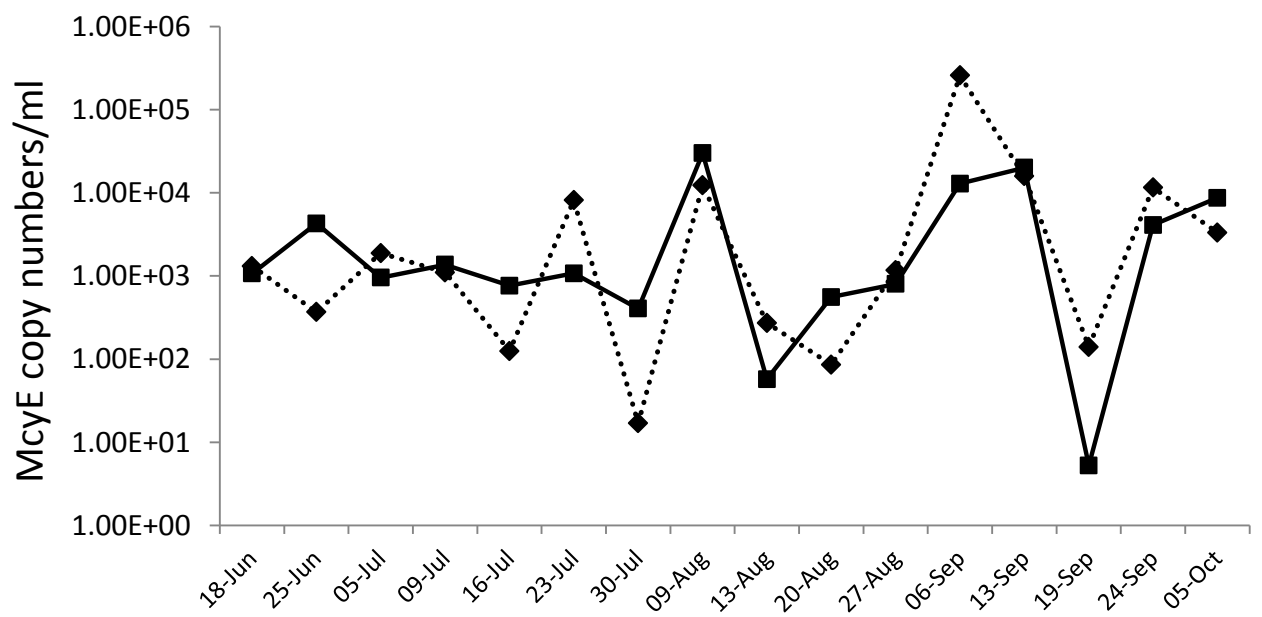

Figure 3: McyE copy numbers of Pine Lake (A) and Pigeon Lake (B) during the sampling period. Microcystis mcyE copy numbers were determined by rt-QPCR, which was showed as mcyE copy numbers per millilitre. Pine lake: Leisure Camp beach $(\bullet)$ and Green Acre beach ( $\bullet$ ); Pigeon Lake: Mission beach ( $\bullet$ ) and Zeiner Park beach $(\boldsymbol{\square})$.

and total cyanobacteria with high sensitivity and specificity. The discordance observed between the rt-QPCR and PPI results from the 4 reference samples with low microcystin concentration $(<1 \mu \mathrm{g} / \mathrm{L})$ (Table 2) could potentially be attribute to enzyme inhibition with other protein phosphatase inhibitors such as okadaic acid and tautomycin in the PPI assay [14]. A more plausible explanation however, is that microcystin detected by PPI assay was produced by microcystinproducing cyanobacteria species other than Microcystis including Planktothrix and Anabaena. Further development of the rt-QPCR assay including other potential toxin-producing cyanobacteria will make it a useful and cost-effective method for measurement and surveillance of spatiotemporal changes in the population of toxinproducing cyanobacteria in individual lake.

A relatively large volume of environmental water samples was required by harvesting the cells via filtration or centrifugation in order to increase detection rate of toxin-producing cyanobacteria $[1,17,24]$. However, the filtration and centrifugation could eliminate or reduce free nucleic acids released from natural degradation of cyanobacteria, resulting in low yields of total DNA. It may also alter the ratio between free DNA and intracellular DNA existing in natural environment. Kumar et al. [30] reported that the presence of free DNA in pond water was detected and $m c y E$ gene from fextracellular DNA was amplified successfully by PCR. They suggested that amplification of $m c y E$ gene directly from the extracellular DNA present in the water was feasible for monitoring the microcystin-producing Microcystis. Based on these findings, the sample preparation for best yield and quality of DNA was optimized during our method development and validation in this study. A better correlation between microcystin concentrations and $m c y E$ gene copy numbers was found in the lake-water sample without manipulation (correlation coefficient: 0.52 ) than that from the supernatant and pellet after centrifugation of the sample (correlation coefficient: 0.45), suggesting that DNA extracted directly from the lake-water was suitable for downstream amplification using rt-QPCR. A possible explanation for this outcome is that a mixed ratio between intracellular genomic DNA and extracellular free DNA may accurately reflect a natural metabolic and synthetic status of Microcystis in lakewater samples. In addition, the volume of samples required for our rtQPCR assay was only $400 \mu$, which was much less than that in other studies $(50 \mathrm{ml}$ to $1 \mathrm{~L}$ of water for processing) $[1,17,31]$. Taken together, optimized DNA extraction directly from lake-water for the rt-QPCR assay will shorten the time of sample preparation, increase efficiency of the assay, and reduce the cost related. It allows a practical application of this method for rapid screening of large quantity of samples during open-water season. 


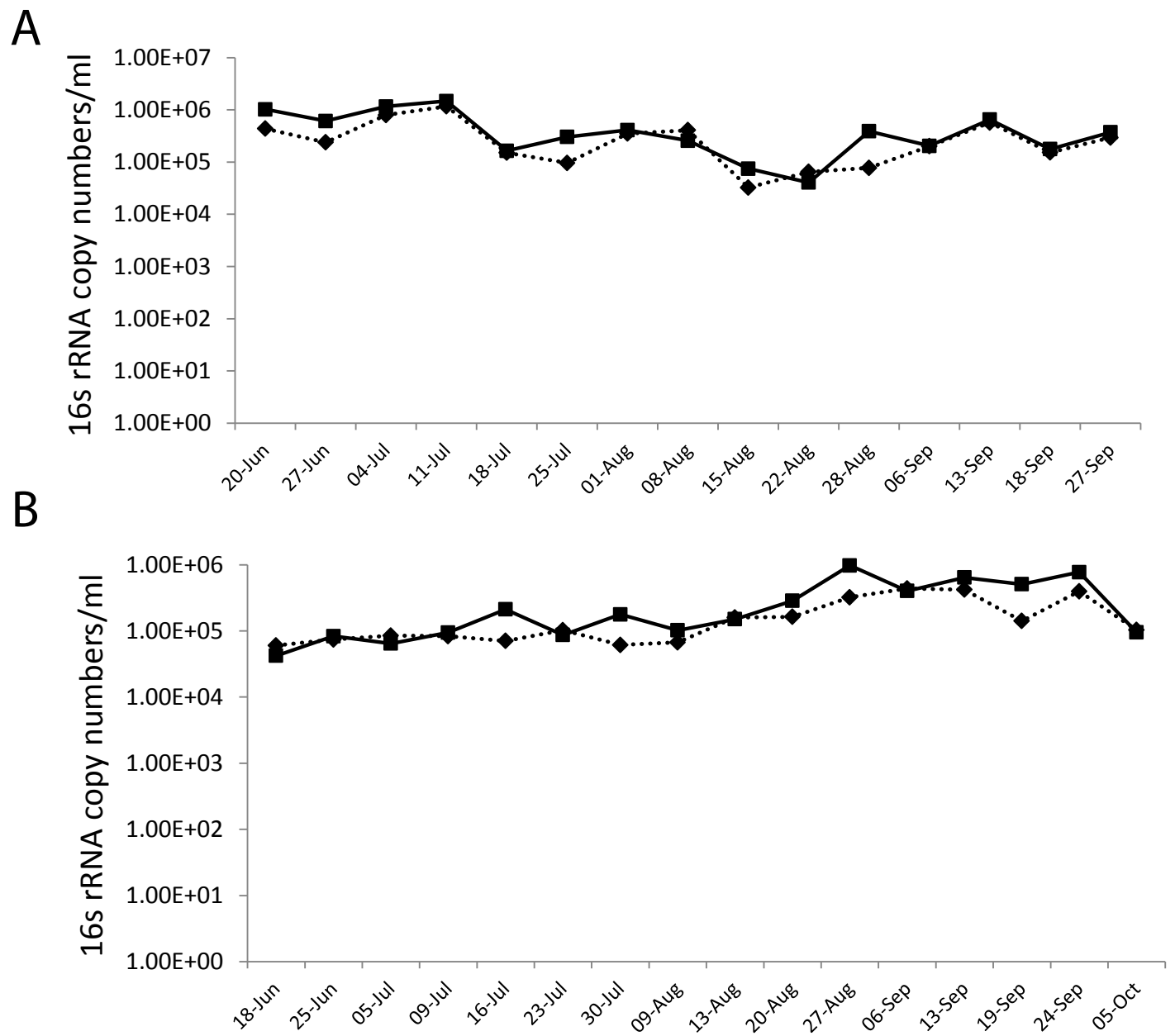

Figure 4: $16 \mathrm{~S}$ rRNA copy numbers of Pine Lake (A) and Pigeon Lake (B) during the sampling period. Cyanobacterial 16s rRNA copy numbers were determined by rt-QPCR, which was showed as 16S rRNA copy numbers per millilitre. Pine Lake: Leisure Camp beach ( $\bullet$ ) and Green Acre beach ( $\bullet$ ); Pigeon Lake: Mission beach ( $\bullet$ and Zeiner Park beach ( $\mathbf{m}$ )

One of the challenges of amplification-based PCR method for environmental water samples is the presence of inhibitors, which may cause false negative results. The presence and level of inhibitory effect on PCR reaction are largely unpredictable. To overcome this difficulty and better control the quality of PCR assay, an internal control has to be integrated into the rt-QPCR assay. Most of studies on cyanobacteria used $16 \mathrm{~S}$ rRNA as an internal control to monitor PCR inhibition $[1,17,25,32]$. However, the wide range of variations of $16 \mathrm{~S}$ rRNA level derived from total cyanobacteria made it difficult to assess the end-point of PCR results, suggesting that $16 \mathrm{~S}$ rRNA may not be an appropriate quality control (QC) for detection of inhibitory effect in lake-water samples. Haugland et al. [26] used salmon testes DNA to evaluate PCR inhibition in the QPCR reaction for Enterococcus measurements. The similar approach was adapted in our rt-QPCR method in order to evaluate inhibitory substances in water samples. Among the 200 samples tested, one reference sample with high microcystin concentration ( $>500 \mu \mathrm{g} / \mathrm{L}$ ) was detected with complete PCR inhibition and no inhibition was detected in other samples, indicating that salmon DNA as an internal control for PCR inhibition is sensitive and reliable.

In this study, the population of microcystin-producing Microcystis alone was examined in selected Alberta lakes for the purpose of method development and validation. Our results indicated that this major microcystin-producing genus was present in $71 \%$ of the lakes with a relatively high level during open-water season, which was in accordance with previous report showing that $25 \%$ to $92 \%$ of the cyanobacterial blooms were hepatotoxic [1]. In addition, among the 15 Alberta lakes that issued with health advisory due to heavy cyanobacterial blooms in 2012, 10 lakes (67\%) were detected with high level of microcystin-producing Microcystis by our rt-QPCR method, suggesting that Microcystis is the main microcystin producer in majority of Alberta lakes. Although Microcystis is the most important and worldwide distributing microcystin-producing species, Planktothrix and Anabaena are also major microcystin-producing cyanobacterial genera. Previous phylogenetic study showed that $m c y E$ gene sequences from different cyanobacteria have their own clusters and maintain exclusion from horizontal gene transfer [33]. Therefore, different microcystin-producing genera can be covered and identified by targeting different regions of $m c y E$ gene using the PCR approach $[1,23,34,35]$

In conclusion, the rt-QPCR assay with integrated internal quality control and optimized sample preparation for lake water were developed and validated in current study. With selected specific primers/probes targeting $m c y E$ gene and $16 \mathrm{~S}$ rRNA gene, the rt-QPCR assay was 
applied to detect and quantify microcystin-producing Microcystis population and its proportion to total cyanobacteria in 45 Alberta lakes during open-water season in 2012. Newly developed rt-QPCR assay was proven to be a simple, rapid and cost-saving assay with high sensitivity and specificity, as well as integrated internal control. It can be used in surveillance program for monitoring microcystin-producing Microcystis during summer season. Further comparative data analyses on the correlation between $m c y E$ copy numbers by rt-QPCR assay and microcystin concentrations measured by other assays (e.g. PPI and LC/ MS) under Alberta health agent will be carried out in near future.

\section{Acknowledgement}

This work was supported by a research grant funded by Alberta Health (RES0015904). We thank Dr. Min Cao for technical support and ACFT for providing the reference water samples and PPI results. We also thank Field Staf from Alberta Health Services for collecting samples and Environmental lab from Provincial Laboratory for Public Health for sample shipment.

\section{References}

1. Rantala A, Rajaniemi-Wacklin P, Lyra C, Lepisto L, Rintala J, et al. (2006) Detection of microcystin-producing cyanobacteria in finnish lakes with genusspecific microcystin synthetase gene $E$ (mcye) pcr and associations with environmental factors. Appl Environ Microbiol 72: 6101-6110.

2. Botes DP, Kruger H, Viljoen CC (1982) Isolation and characterization of four toxins from the blue-green alga, microcystis aeruginosa. Toxicon 20: 945-954.

3. Goldberg J, Huang HB, Kwon YG, Greengard P, Nairn AC, et al. (1995) Three-dimensional structure of the catalytic subunit of protein serine/threonine phosphatase-1. Nature 376: 745-753.

4. Bagu JR, Sonnichsen FD, Williams D, Andersen RJ, Sykes BD, et al. (1995) Comparison of the solution structures of microcystin-Ir and motuporin. Nat struct Biol 2: 114-116.

5. MacKintosh C, Beattie KA, Klumpp S, Cohen P, Codd GA (1990) Cyanobacterial microcystin-Ir is a potent and specific inhibitor of protein phosphatases 1 and $2 a$ from both mammals and higher plants. FEBS Lett 264: 187-192.

6. Nishiwaki-Matsushima R, Ohta T, Nishiwaki S, Suganuma M, Kohyama K et al. (1992) Liver tumor promotion by the cyanobacterial cyclic peptide toxin microcystin-Ir. J Cancer Res Clin Oncol 118: 420-424.

7. Ohta T, Nishiwaki R, Yatsunami J, Komori A, Suganuma M, et al. (1992) Hyperphosphorylation of cytokeratins 8 and 18 by microcystin-Ir, a new liver 19 tumor promoter, in primary cultured rat hepatocytes. Carcinogenesis 13 2443-2447.

8. Sturgeon SA and Towner RA (1999) In vivo assessment of microcystin-Irinduced hepatotoxicity in the rat using proton nuclear magnetic resonance (1h-nmr) imaging. Biochim Biophys Acta 1454: 227-235.

9. Dittmann E, Neilan BA, Erhard M, von Dohren H and Borner T (1997) Insertiona mutagenesis of a peptide synthetase gene that is responsible for hepatotoxin production in the cyanobacterium microcystis aeruginosa pcc 7806 . Mol Microbiol 26: 779-787.

10. Tillett D, Dittmann E, Erhard M, von Dohren H, Borner T, et al. (2000) Structura organization of microcystin biosynthesis in microcystis aeruginosa pcc7806 An integrated peptide-polyketide synthetase system. Chem Biol 7: 753-764.

11. Christiansen G, Fastner J, Erhard M, Borner T, Dittmann E (2003) Microcystin biosynthesis in planktothrix: Genes, evolution, and manipulation. J Bacteriol 185: 564-572.

12. Rouhiainen L, Vakkilainen T, Siemer BL, Buikema W, Haselkorn R, et al. (2004) Genes coding for hepatotoxic heptapeptides (microcystins) in the cyanobacterium anabaena strain 90. Appl Environ Microbiol 70: 686-892.

13. Nishizawa T, Ueda A, Asayama M, Fujii K, Harada K, et al. (2000) Polyketide synthase gene coupled to the peptide synthetase module involved in the biosynthesis of the cyclic heptapeptide microcystin. J Biochem 127: 779-789.

14. El Semary N (2010) Modern methods for detection and elimination of microcystins toxins produced by cyanobacteria: Mini-review. Journal of Applied Sciences 10: 1662-1666

15. Espy MJ, Uhl JR, Sloan LM, Buckwalter SP, Jones MF, et al. (2006) Realtime pcr in clinical microbiology: Applications for routine laboratory testing. Clin Microbiol Rev 19: 165-256.
16. Tillett D, Parker DL, Neilan BA (2001) Detection of toxigenicity by a probe for the microcystin synthetase a gene (mcya) of the cyanobacterial genus microcystis: Comparison of toxicities with 16s rRNA and phycocyanin operon (phycocyanin intergenic spacer) phylogenies. Appl Environ Microbiol 67: 2810-2818.

17. Vaitomaa J, Rantala A, Halinen K, Rouhiainen L, Tallberg P, et al. (2003) Quantitative real-time pcr for determination of microcystin synthetase e copy numbers for microcystis and anabaena in lakes. Appl Environ Microbiol 69: 7289-7297.

18. Rinta-Kanto JM, Ouellette AJ, Boyer GL, Twiss MR, Bridgeman TB, et al. (2005) Quantification of toxic microcystis spp. During the 2003 and 2004 blooms in western lake erie using quantitative real-time pcr. Environ Sci Technol 39: 4198-4205.

19. Stotts RR, Namikoshi M, Haschek WM, Rinehart KL, Carmichael WW, et al (1993) Structural modifications imparting reduced toxicity in microcystins from microcystis spp. Toxicon 31: 783-789.

20. Harada K, Ogawa K, Matsuura K, Nagai H, Murata H, et al. (1991) Isolation of two toxic heptapeptide microcystins from an axenic strain of microcystis aeruginosa, k-139. Toxicon 29: 479-489.

21. Zurawell RW (2005) Alberta environment cyanotoxin program status report 2010.

22. Glowacka J, Szefel-Markowska M, Waleron M, Lojkowska E, Waleron K (2011) Detection and identification of potentially toxic cyanobacteria in polish water bodies. Acta Biochim Pol 58: 321-333

23. Sipari H, Rantala-Ylinen A, Jokela J, Oksanen I, Sivonen K (2010) Development of a chip assay and quantitative pcr for detecting microcystin synthetase e gene expression. Appl Environ Microbiol 76: 3797-3805.

24. Lin S, Shen J, Liu Y, Wu X, Liu Q, et al. (2011) Molecular evaluation on the distribution, diversity, and toxicity of microcystis (cyanobacteria) species from lake ulungur--a mesotrophic brackish desert lake in xinjiang, china. Environ Monit Assess 175: 139-150.

25. Koskenniemi K, Lyra C, Rajaniemi-Wacklin P, Jokela J, Sivonen K (2007) Quantitative real-time pcr detection of toxic nodularia cyanobacteria in the baltic sea. Appl Environ Microbiol 73: 2173-2179.

26. Haugland RA, Siefring SC, Wymer LJ, Brenner KP, Dufour AP (2005) Comparison of enterococcus measurements in freshwater at two recreational beaches by quantitative polymerase chain reaction and membrane filter culture analysis. Water Res 39: 559-568.

27. Pfaffl MW (2001) A new mathematical model for relative quantification in realtime rt-pcr. Nucleic Acids Res 29: e45.

28. Baker JA, Neilan BA, Entsch B, McKay DB (2001) Identification of cyanobacteria and their toxigenicity in environmental samples by rapid molecular analysis. Environ Toxicol 16: 472-482.

29. Baker JA, Entsch B, Neilan BA, McKay DB (2002) Monitoring changing toxigenicity of a cyanobacterial bloom by molecular methods. Appl Environ Microbiol 68: 6070-6076.

30. Kumar A, Kumar A, Rai AK, Tyagi MB (2011) PCR-based detection of mcy genes in blooms of microcystis and extracellular DNA of pond water. Afr Microbiol Res 5: 374-381.

31. Ngwa F, Madramootoo C, Jabaji S (2012) Monitoring toxigenic microcystis strains in the missisquoi bay, quebec, by pcr targeting multiple toxic gene loci. Environ Toxicol.

32. Al-Tebrineh J, Gehringer MM, Akcaalan R, Neilan BA (2011) A new quantitative pcr assay for the detection of hepatotoxigenic cyanobacteria. Toxicon 57: 546 554

33. Rantala A, Fewer DP, Hisbergues M, Rouhiainen L, Vaitomaa J, et al. (2004) Phylogenetic evidence for the early evolution of microcystin synthesis. Proc Natl Acad Sci U S A 101: 568-573.

34. Mbedi S, Welker M, Fastner J, Wiedner C (2005) Variability of the microcystin synthetase gene cluster in the genus planktothrix (oscillatoriales, cyanobacteria). FEMS Microbiol Lett 245: 299-306.

35. Jungblut AD, Neilan BA (2006) Molecular identification and evolution of the cyclic peptide hepatotoxins, microcystin and nodularin, synthetase genes in three orders of cyanobacteria. Arch Microbiol 185: 107-114. 